\title{
GMR
}

\section{Identification of differentially expressed genes in pathways of cerebral neurotransmission of anovulatory mice}

\author{
M.A. Azevedo Jr. and I.D.C.G. Silva \\ Laboratório de Ginecologia Molecular, \\ Universidade Federal de São Paulo, São Paulo, SP, Brasil \\ Corresponding authors: M.A. Azevedo Jr. / I.D.C.G. Silva \\ E-mail: marcosazevedojr@gmail.com / Ismael.dale@gmail.com
}

Genet. Mol. Res. 16 (3): gmr16039622

Received January 18, 2017

Accepted September 4, 2017

Published September 27, 2017

DOI http://dx.doi.org/10.4238/gmr16039622

Copyright (C) 2017 The Authors. This is an open-access article distributed under the terms of the Creative Commons Attribution ShareAlike (CC BY-SA) 4.0 License.

\begin{abstract}
Polycystic ovary syndrome is the classic example of loss of functional cyclicity and anomalous feedback. In this case, the excessive extra-glandular production and conversion of androgens to estrogens are the pathophysiological basis of the chronic anovulation. The literature describes an experimental model of the polymicrocystic ovary in obese diabetic mice with insulin resistance. The fact that these animals exhibit obesity, insulin resistance, and infertility demonstrates their skill as an experimental model for polycystic ovary. A recent study using long protocol for up to 40 weeks showed that anovulatory and obese mice transplanted with adipose tissue from animals with normal weight have multiple changes in their phenotype. These changes include reduction of body weight, prevention of obesity, insulin level normalization, and insulin tolerance tests, preventing the elevation of steroids and especially the reversal of fertility restoration with anovulation. Considering that there are close relationships between the ovulation process and the central nervous system, we propose to evaluate the gene expression levels of 84 different genes involved in neurotransmission and insulin pathways in addition to examining the
\end{abstract}

Genetics and Molecular Research 16 (3): gmr16039622 
neurolipidosis differential murine brain before and after reversal of anovulation. The present study showed changes in gene expression of molecular markers in brain tissue of animals for brain neurotransmission pathways as well as pathways for insulin. GABAergic genes, muscarinic, serotonin receptors, receptor tyrosine kinase, and genes of interleukin 6 showed overexpression profile. There was also a change in the lipid content in anovulatory brain, obesity, and insulin resistant mice (Ob-/Ob-) compared with controls. The re-introduction of leptin in these animals appears to reverse, at least in part, this profile.

Key words: Differentially expressed genes; Neurotransmitter; Anovulation

\section{INTRODUCTION}

Polycystic ovary syndrome (PCOS) is one of the most frequent observed endocrinopathies of women during their reproductive age, and it is estimated to affect $6.8 \%$ of them (DiamantiKandarakis et al., 1999). Different from the previous hypothesis, PCOS seems now to be more related to insulin resistance rather than to the initially regarded as hyperandrogenism in reproductive age. Indeed, the insulin resistance and hyperinsulinemia participate in reproductive as well as metabolic disturbances associated with PCOS (Diamanti-Kandarakis, 2008). Implications may even extend beyond the reproductive axis, creating a need for a modified therapeutic management of affected women, especially from the cardiovascular point-of-view.

Another hallmark of the syndrome is a high GnRH pulse frequency resulting in elevated LH levels and LH/FSH ratio stimulating ovarian androgen production. It has been demonstrated that these women have decreased hypothalamic sensitivity to progesteronemediated feedback, in addition to reduced luteal phase progesterone production resulting from frequent anovulatory cycles. This effect is mediated by androgens and aggravated by insulin resistance (Blanksby and Mitchell, 2010).

In animal models, a similar reproductive endocrine phenotype occurs when the Leptin gene is knockdown. Despite the well-known fact that the central nervous system plays a major role in PCOS, very little is known about the specific molecular events that take place inside the brain during the anovulatory process and metabolic syndrome.

Therefore, in the present article, our aim was to analyze the expression of 84 genes involved in modulating the biological processes of neurotransmitter biosynthesis, uptake, transport, and signaling through brain neurotransmitter receptors of female obese, insulinresistant, non-ovulating, leptin-deficient $(\mathrm{Ob} / \mathrm{Ob})$ mice. Neurotransmission gene expression was further analyzed in the brain after the re-introduction of leptin in these animals.

\section{MATERIAL AND METHODS}

\section{In vivo murine studies}

Six-week-old female obese $o b / o b$ mice together with their lean littermate controls were used. All procedures were approved by the Federal University of São Paulo Institutional Animal Care and Use Committee. Animals were housed with ad libitum access to food and water.

All animals were maintained in a temperature-controlled environment at $\pm 24^{\circ} \mathrm{C}$ under a 12:12-h light-dark cycle and handled at least one time per week. Diet was a regular chow

Genetics and Molecular Research 16 (3): gmr16039622 
(F6 Rodent Diet; Harlan Teklad, Madison, WI, USA) comprised of 52\% carbohydrate, $18 \%$ fat, and $31 \%$ protein by calorie or KD (F-3666; Bio-Serv, Frenchtown, NJ, USA) comprised of $0.4 \%$ carbohydrate, $95 \%$ fat, and $4.5 \%$ protein by calorie. Animal groups were divided as follows: 1 Control group (CG): Composed of 5 normal weight, 2 to 3 months of age B6.V-Lepob/J mice. After sacrifice brains were removed and kept in liquid nitrogen until use. 2- Obesity group (OG): Composed of 5 overweight, anovulatory, 2 to 3 months of age B6.V-Lepob/J mice. After sacrifice brains were removed and kept in liquid nitrogen until use. 3- Obesity group transplanted (OGT): Composed of 5 overweight, anovulatory, 2 to 3 months of age B6.V-Lepob/J mice that were recipient to fat transplantation from ovulating mice and sacrificed after 7 days of transplant. After sacrifice brains were removed and kept in liquid nitrogen until use.

\section{Fat tissue transplant}

Five female leptin-deficient (B6.V-Lep ${ }^{o b} / \mathrm{J}$, referred to as $o b / o b$ ) mice and their lean littermates were obtained from the animal facility of our University. A group of $o b / o b$ mice received fat tissue transplantation as described by Gavrilova et al. (2000). Briefly, gonadal fat from wild-type littermates euthanized by cervical dislocation was placed in sterile PBS and cut into small pieces. The grafts were implanted subcutaneously through small incisions in the shaved skin of the back of recipient $o b / o b$ mice anesthetized with isoflurane.

Approximately $1 \mathrm{~g}$ tissue was transplanted per mouse. Incisions were closed using wound clips and mice observed for wound closure. The second group of $o b / o b$ mice was sham-operated. Mice were observed for 7 days after transplant, at which point they were sacrificed by cervical dislocation under isoflurane anesthesia.

\section{RT profiler PCR-array mouse neurotransmitter receptors and regulators}

The Mouse Neurotransmitter Receptors and Regulators $\mathrm{RT}^{2}$ Profiler ${ }^{\mathrm{TM}}$ PCR Array, containing 84 genes involved in neurotransmission, was applied and run in triplicates together with five housekeeping genes (18srRNA, HPRT1, RPL13A, GAPD, and ACTB). Whole mouse brain was subjected to RNA extraction, cDNA synthesis, and PCR array as recommended by the manufacturer.

The amount of total RNA was quantified in $n g / \mu \mathrm{L}$ using the Nanodrop device. Gel electrophoresis of selected samples was performed on denaturating $2.0 \%$ agarose gel containing ethidium bromide and revealed the two rRNA bands corresponding to $28 \mathrm{~S}$ and $18 \mathrm{~S}$. Sample purity was determined by calculating the $260 / 280$ ratios and found within the 1.6 to 2.2 range in all samples.

The samples were stored at $-80^{\circ} \mathrm{C}$ and cDNA was obtained by using the Reaction Ready ${ }^{\mathrm{TM}}$ First-Strand cDNA Synthesis Kit (SuperArray), and the procedures were performed following the manufacturer's instructions.

Negative control for genomic DNA and contaminating RNA were also conducted in each sample. Amplification, data acquisition, and the melting curve were carried out by iCycler iQ (Bio-Rad Laboratories, Hercules, CA, USA). The Ct and the melting curve of every gene were observed for every animal.

The threshold to determine the $\mathrm{Ct}$ value for each gene was automatically established by the iCycler iQ version 3 software that determined the SD of the points forming the baseline. Results are reported as $\mathrm{Ct}$ and normalized with the housekeeping gene 18SrRNA. The foldchange ratio for each gene was compared between the brain anovulatory groups and healthy mice counterparts. Analysis of variance followed by the Dunnett post hoc multiple comparison

Genetics and Molecular Research 16 (3): gmr16039622 
tests was used to compare the Ct results generated by the RT Profiler PCR Array between anovulatory groups against the control group. Genes are reported as differently expressed between groups when the fold-change was at least three-fold up-regulated or down-regulated, and the $\mathrm{P}$ value (analysis of variance and post-test) was lower than or equal to 0.05 .

\section{Neurotransmitter receptors analyzed}

Acetylcholine Receptors: Anxa9, Chrm3.

Muscarinic Acetylcholine Receptors: Chrm 1, Chrm2, Chrm3, Chrm4, Chrm5.

Adrenocorticotropin Receptors: $M c 2 r$.

Bombesin Receptors: Brs3, Grpr.

Cholecystokinin Receptors: Cckar, Cckbr.

Dopamine Receptors: Drd1a, Drd2, Drd3, Drd4, Drd5.

GABA-A Receptors: Gabra1, Gabra2, Gabra3, Gabra4, Gabra5, Gabra6, Gabrb2, Gabrb3, Gabrd, Gabrg1, Gabrg2, Gabrp, Gabrq, Gabrr1, Gabrr2, Glra1, Glra2, Glra3, Glra4. Gastrin Receptors: Cckar, Cckbr, Galr1, Galr2, Galr3.

Neuromedin U Receptors: Nmur1, Nmur2.

Neuropeptide Receptors: Npffr1 (Gpr147), Npffr2 (Gpr74), Ntsr1.

Neuropeptide Y Receptors: Gpr103, Prokr1 (Gpr73), Prokr2 (Gpr73l1), Gpr83, Npy1r, Npy2r, Npy5r, Npy6r, Pgr15l, Ppyr1, Prlhr (Gpr10).

Peptide YY Receptors: Npy1r, Npy2r, Npy5r, Npy6r, Ppyr1.

Somatostatin Receptors: Sstr1, Sstr2, Sstr3, Sstr4, Sstr5.

Tachykinin Receptors: Tacr1, Tacr2, Tacr3.

Other Neurotransmitter Receptors: Chrna1, Chrna2, Chrna3, Chrna4, Chrna5, Chrna6, Chrna 7, Chrnb1, Chrnb2, Chrnb3, Chrnb4, Chrnd, Chrne, Chrng, Glrb, Htr3a.

\section{Regulation of neurotransmitter levels}

Neurotransmitter Biosynthesis: Chat, Gad1, Slc5a7

Neurotransmitter Catabolism: Ache, Comt, Maoa.

\section{Immunohistochemistry}

To further confirm our results and also identify the localization of protein expression in the brain, immunohistochemistry was also performed for the most up-regulated genes, Gabrb3 and Gabrg2.

\section{RESULTS}

Among the 84 genes studied between the brain of normal and obese mice, we identified 34 as differentially expressed after statistical analysis. Of that, 13 were considered down-regulated and 21 up-regulated (Table 1). Remarkably, after only 7 days of the fat tissue transplant, only one gene, Tacr3, remained up-regulated in the brain of the transplanted group.

A gene expression analysis was performed for all the genes described before and after transplantation, it was possible to notice that the great majority of the genes presented were hyperexpressed (Figure 1) at the moment before transplantation and after 7 days of the Transplantation, it was possible to identify a notable reversal of this characteristic (Figure 2).

Genetics and Molecular Research 16 (3): gmr16039622 
Table 1. Gene expression level in of the brain analysis of anovulatory mice.

\begin{tabular}{|c|c|c|c|c|}
\hline Functional gene groupings & $\begin{array}{l}\text { Obese mice fold- } \\
\text { change }\end{array}$ & P value & 7 days of transplant & P value \\
\hline \multicolumn{5}{|l|}{ Neurotransmitter Receptors } \\
\hline \multicolumn{5}{|l|}{ Acetylcholine Receptors } \\
\hline Anxa9 & -4.11 & 0.020670 & -9.32 & 0.000062 \\
\hline Chrm3 & -1.79 & 0.974012 & -7.57 & 0.000000 \\
\hline \multicolumn{5}{|c|}{ Muscarinic Acetylcholine Receptors } \\
\hline Chrml & 48.84 & 0.091955 & -3.07 & 0.000211 \\
\hline Chrm2 & 2.66 & 0.150482 & -2.10 & 0.001728 \\
\hline Chrm3 & -1.79 & 0.974012 & -7.57 & 0.000000 \\
\hline Chrm4 & 1.69 & 0.214442 & -2.58 & 0.001921 \\
\hline Chrm5 & 1.08 & 0.370781 & -2.17 & 0.006942 \\
\hline \multicolumn{5}{|c|}{ Adrenocorticotropin Receptors } \\
\hline$M c 2 r$ & -3.34 & 0.068337 & -3.07 & 0.000145 \\
\hline \multicolumn{5}{|l|}{ Bombesin Receptors } \\
\hline Brs3 & -6.92 & 0.023793 & -3.07 & 0.016254 \\
\hline Grpr & -2.53 & 0.708941 & -2.50 & 0.000156 \\
\hline \multicolumn{5}{|l|}{ Cholecystokinin Receptors } \\
\hline Cckar & -4.56 & 0.051037 & -5.74 & 0.007709 \\
\hline Cckbr & -1.03 & 0.427239 & -4.66 & 0.003998 \\
\hline \multicolumn{5}{|l|}{ Dopamine Receptors } \\
\hline Drdla & -1.31 & 0.688211 & -6.59 & 0.000385 \\
\hline $\operatorname{Drd2}$ & -1.31 & 0.712160 & -5.17 & 0.002160 \\
\hline $\operatorname{Drd3}$ & -1.18 & 0.575474 & -1.48 & 0.225068 \\
\hline $\operatorname{Drd4}$ & -2.53 & 0.394967 & -10.34 & 0.000607 \\
\hline Drd5 & -4.11 & 0.116153 & -6.36 & 0.000010 \\
\hline \multicolumn{5}{|l|}{ GABA-A Receptors } \\
\hline Gabral & 58.08 & 0.079586 & -4.20 & 0.000085 \\
\hline Gabra2 & 3.05 & 0.142180 & -2.68 & 0.003229 \\
\hline Gabra3 & 17.27 & 0.102259 & 1.44 & 0.750036 \\
\hline Gabra4 & 20.53 & 0.121194 & -1.54 & 0.255686 \\
\hline Gabra5 & 8.06 & 0.100040 & -5.94 & 0.005289 \\
\hline Gabra6 & 5.13 & 0.120686 & -14.12 & 0.000000 \\
\hline Gabrb2 & 22.78 & 0.095446 & -5.54 & 0.003224 \\
\hline Gabrb3 & 232.32 & 0.070995 & -2.97 & 0.000424 \\
\hline Gabrd & 2.16 & 0.170917 & -5.74 & 0.000006 \\
\hline Gabrgl & 3.76 & 0.267210 & 1.26 & 0.403649 \\
\hline Gabrg2 & 164.28 & 0.071247 & -1.09 & 0.443929 \\
\hline Gabrp & 1.16 & 0.333973 & -3.41 & 0.000438 \\
\hline Gabrq & -1.79 & 0.967364 & -3.18 & 0.005660 \\
\hline Gabrrl & -2.62 & 0.444059 & -2.58 & 0.100276 \\
\hline Gabrr2 & -1.56 & 0.651516 & -2.97 & 0.006893 \\
\hline Glral & -2.53 & 0.479330 & -2.50 & 0.117328 \\
\hline Glra2 & -2.13 & 0.602807 & -2.87 & 0.006055 \\
\hline Glra3 & 3.89 & 0.115340 & -1.09 & 0.700959 \\
\hline Glra4 & -2.62 & 0.665324 & -3.41 & 0.022184 \\
\hline \multicolumn{5}{|l|}{ Gastrin Receptors } \\
\hline Cckar & -4.56 & 0.051037 & -5.74 & 0.007709 \\
\hline Cckbr & -1.03 & 0.427239 & -4.66 & 0.003998 \\
\hline Galr1 & -4.72 & 0.016241 & -5.74 & 0.000000 \\
\hline Galr2 & -2.81 & 0.304981 & -2.87 & 0.148685 \\
\hline Galr3 & -2.71 & 0.260494 & -1.13 & 0.301424 \\
\hline \multicolumn{5}{|l|}{ Neuromedin U Receptors } \\
\hline Nmurl & -1.36 & 0.487064 & -3.41 & 0.005531 \\
\hline Nmur 2 & -1.79 & 0.953509 & -3.07 & 0.000493 \\
\hline \multicolumn{5}{|l|}{ Neuropeptide Receptors } \\
\hline Npffrl (Gprl47) & -2.13 & 0.840610 & -8.69 & 0.000004 \\
\hline Npffr2 (Gpr74) & 1.47 & 0.230477 & -1.96 & 0.002482 \\
\hline Ntsrl & 1.16 & 0.292900 & -2.03 & 0.019582 \\
\hline \multicolumn{5}{|l|}{ Neuropetide Y Receptors } \\
\hline Qrfpr & 4.32 & 0.067335 & -1.16 & 0.357521 \\
\hline Prokrl (Gpr73) & -3.84 & 0.170310 & -2.41 & 0.095515 \\
\hline Prokr2 (Gpr7311) & -1.99 & 0.833335 & -1.09 & 0.468912 \\
\hline Gpr83 & 1.88 & 0.190744 & -7.06 & 0.000002 \\
\hline Npylr & 1.64 & 0.239341 & -1.83 & 0.046601 \\
\hline Npy $2 r$ & 1.53 & 0.251263 & -1.54 & 0.054869 \\
\hline
\end{tabular}

Genetics and Molecular Research 16 (3): gmr16039622 
Table 1. Continued.

\begin{tabular}{|c|c|c|c|c|}
\hline Npy5r & 10.27 & 0.097446 & -2.03 & 0.000747 \\
\hline Npy6r & -3.23 & 0.276981 & -4.66 & 0.015249 \\
\hline Pgrl5l & 1.58 & 0.225764 & 1.21 & 0.114330 \\
\hline Ppyrl & -2.20 & 0.609688 & -3.41 & 0.001583 \\
\hline Prlhr (Gprl0) & -1.79 & 0.945939 & -3.18 & 0.004313 \\
\hline \multicolumn{5}{|c|}{ Peptide YY Receptors } \\
\hline Npylr & 1.64 & 0.239341 & -1.83 & 0.046601 \\
\hline Npy2r & 1.53 & 0.251263 & -1.54 & 0.054869 \\
\hline Npy $5 r$ & 10.27 & 0.097446 & -2.03 & 0.000747 \\
\hline Npy6r & -3.23 & 0.276981 & -4.66 & 0.015249 \\
\hline Ppyrl & -2.20 & 0.609688 & -3.41 & 0.001583 \\
\hline \multicolumn{5}{|c|}{ Somatostatin Receptors } \\
\hline Sstrl & -1.31 & 0.888664 & -1.09 & 0.499841 \\
\hline Sstr2 & 11.39 & 0.120448 & -1.83 & 0.182661 \\
\hline Sstr3 & -3.01 & 0.629782 & -5.35 & 0.000059 \\
\hline Sstr4 & 2.08 & 0.889827 & -1.43 & 0.214445 \\
\hline Sstr 5 & 2.16 & 0.174080 & -1.16 & 0.357521 \\
\hline \multicolumn{5}{|c|}{ Tachykinin Receptors } \\
\hline Tacrl & -2.36 & 0.844945 & -2.41 & 0.002405 \\
\hline Tacr2 & -6.23 & 0.010367 & -11.47 & 0.001098 \\
\hline Tacr3 & 14.03 & 0.109652 & 4.53 & 0.026174 \\
\hline \multicolumn{5}{|c|}{ Other Neurotransmitter Receptors } \\
\hline Chrnal & -6.92 & 0.001124 & -7.06 & 0.000001 \\
\hline Chrna2 & 2.01 & 0.436780 & -2.33 & 0.170204 \\
\hline Chrna3 & -1.27 & 0.579056 & -9.65 & 0.000013 \\
\hline Chrna4 & 2.23 & 0.182199 & -4.50 & 0.022366 \\
\hline Chrna5 & -4.89 & 0.066526 & -2.41 & 0.078253 \\
\hline Chrna6 & -2.36 & 0.552564 & -2.97 & 0.000157 \\
\hline Chrna7 & -3.23 & 0.328895 & -3.18 & 0.047374 \\
\hline Chrnbl & -3.58 & 0.162537 & -1.96 & 0.113367 \\
\hline Chrnb2 & 8.34 & 0.173478 & 1.26 & 0.326259 \\
\hline Chrnb3 & -2.81 & 0.310689 & -1.89 & 0.101501 \\
\hline Chrnb4 & -3.97 & 0.123375 & -7.84 & 0.000201 \\
\hline Chrnd & 4.96 & 0.124909 & -1.25 & 0.166996 \\
\hline Chrne & -15.35 & 0.015633 & -10.70 & 0.013186 \\
\hline Chrng & -1.99 & 0.823609 & -2.25 & 0.028641 \\
\hline Glrb & 94.35 & 0.066486 & 1.49 & 0.538925 \\
\hline$H$ tr3a & -4.26 & 0.175870 & -2.87 & 0.089983 \\
\hline \multicolumn{5}{|c|}{ Regulation of Neurotransmitter Levels } \\
\hline \multicolumn{5}{|c|}{ Neurotransmitter Biosynthesis } \\
\hline Chat & -1.14 & 0.656465 & -2.87 & 0.040200 \\
\hline Gadl & 27.10 & 0.086453 & -2.33 & 0.093293 \\
\hline Slc5a7 & 4.63 & 0.167870 & 1.26 & 0.493606 \\
\hline \multicolumn{5}{|c|}{ Neurotransmitter Catabolism } \\
\hline Ache & 2.08 & 0.181419 & -2.97 & 0.000575 \\
\hline Comt & -1.40 & 0.979578 & -6.36 & 0.000836 \\
\hline Maoa & 3.51 & 0.108982 & -2.68 & 0.002493 \\
\hline
\end{tabular}

\section{Immunohistochemistry analysis}

The results obtained in the immunohistochemical tests confirmed the molecular findings by using antibodies specific for the differentially expressed genes found in brain tissue of mice (Figures 3 and 4); it is possible to verify the presence of specific large-scale brain tissue antibodies.

Genetics and Molecular Research 16 (3): gmr16039622 


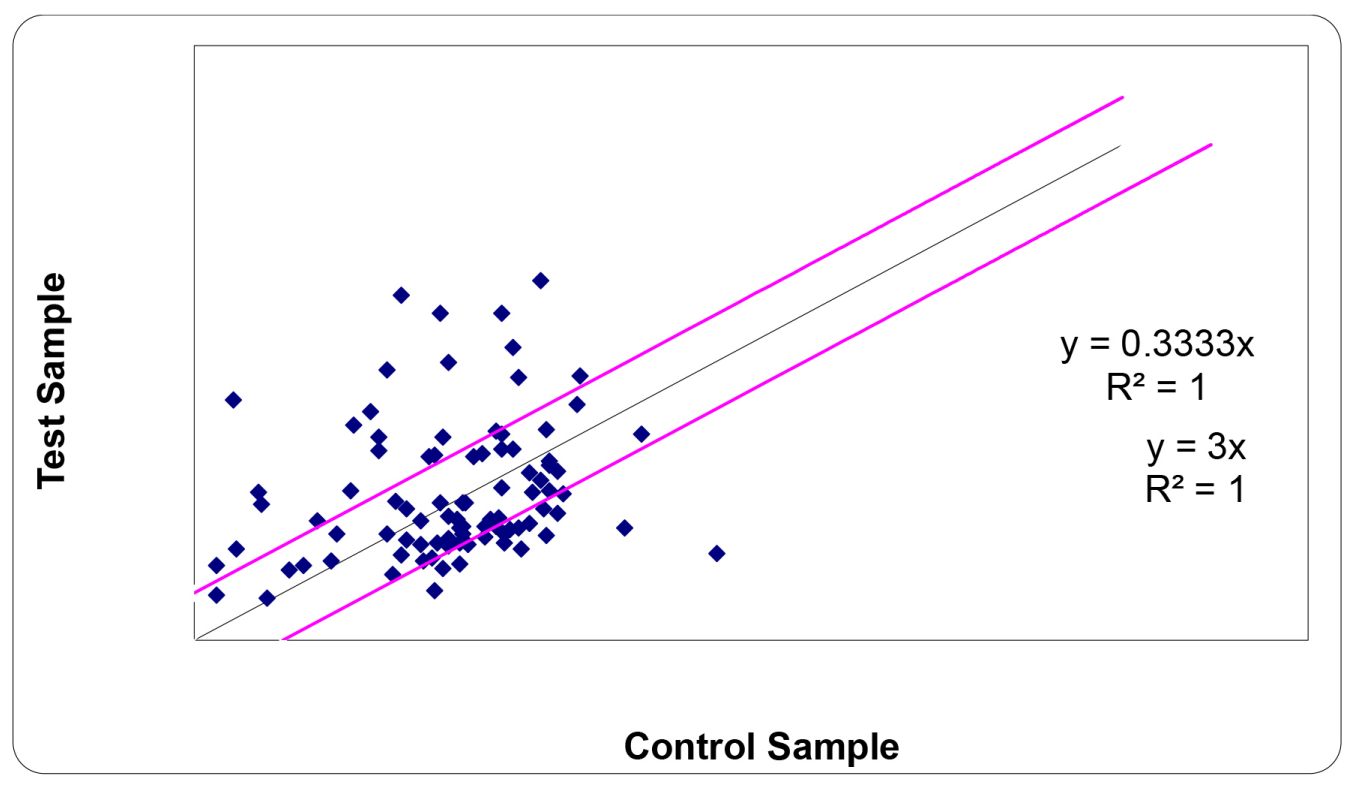

Figure 1. Gene expression in brain before transplantation.

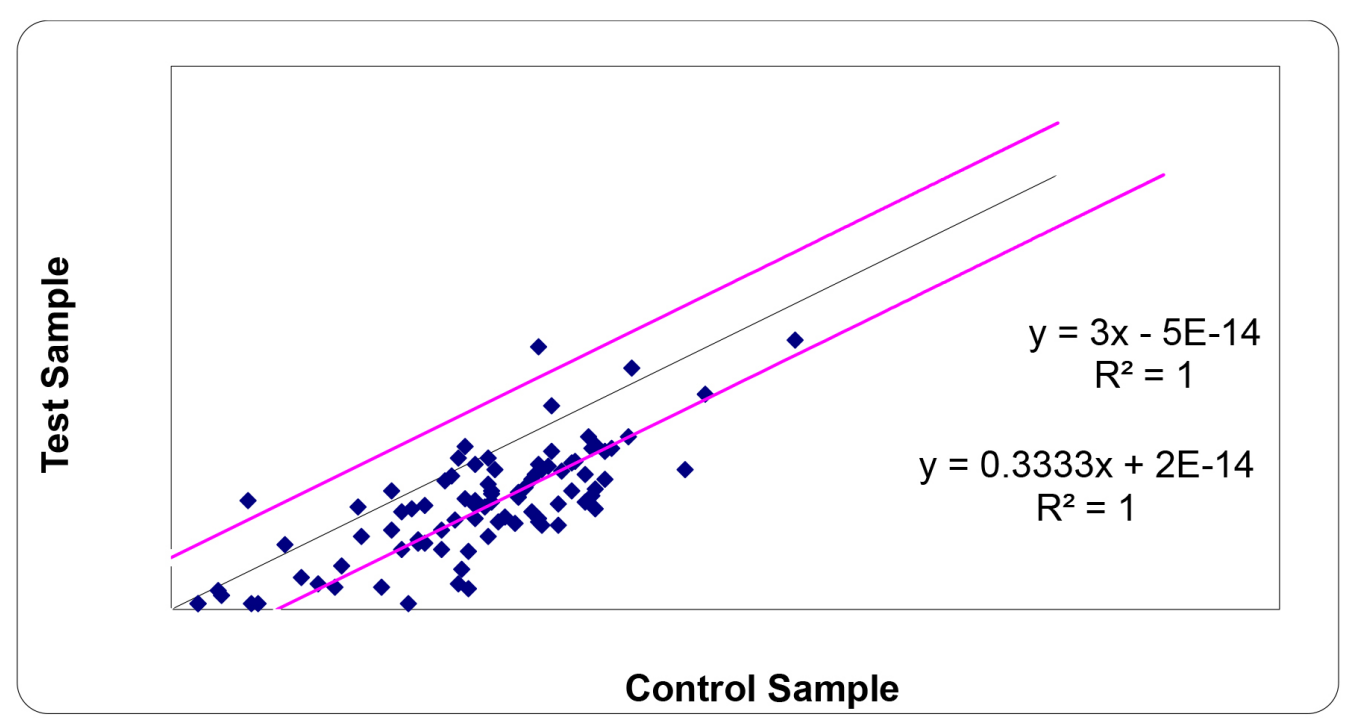

Figure 2. Gene expression in brain after 7 days of fat tissue transplantation.

Genetics and Molecular Research 16 (3): gmr16039622 

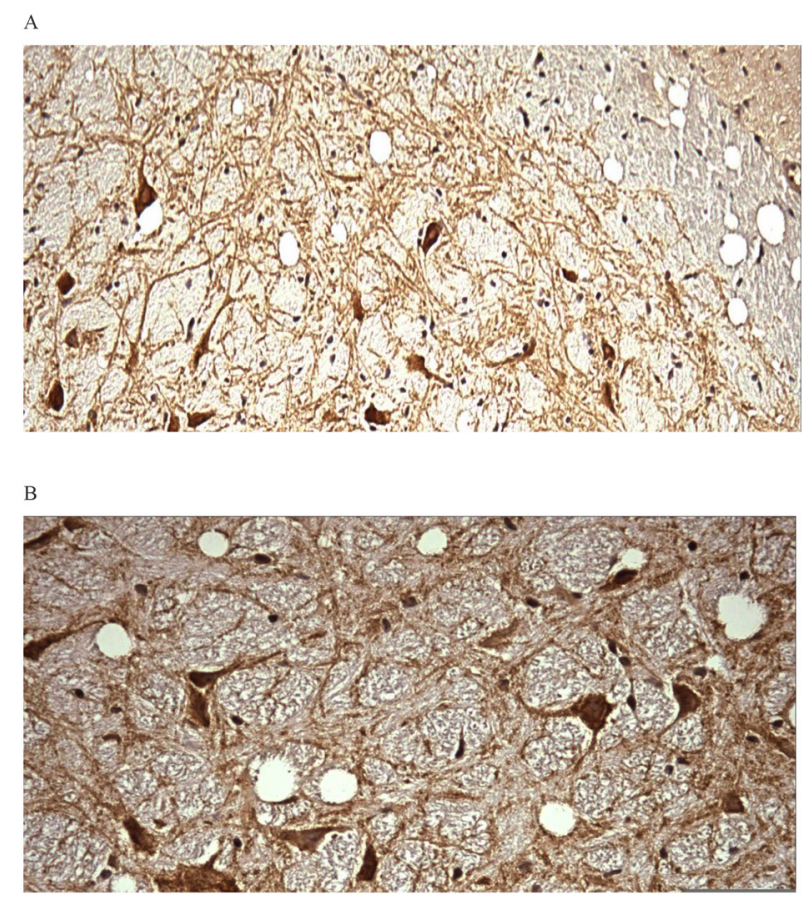

Figure 3. A. Anti- Gabrg2. B. Anti- Gabrg2 (Increased A: 200X; B: 400X).
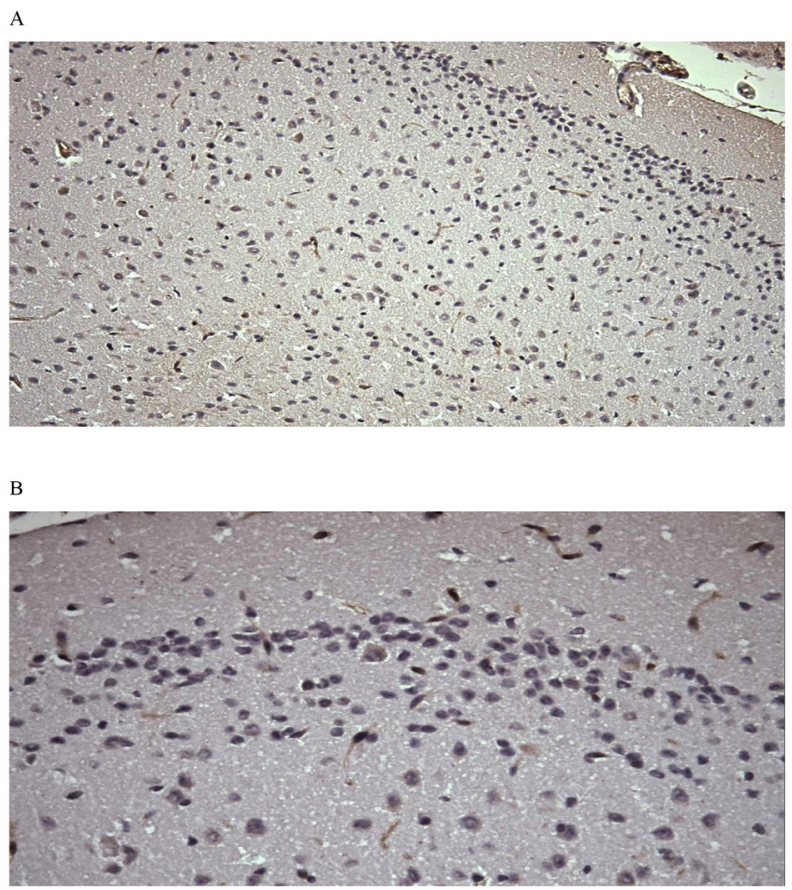

Figure 4. A. Anti-Gabrb3. B. Anti-Gabrb3 (Increased A: 200X; B: 400X).

Genetics and Molecular Research 16 (3): gmr16039622 


\section{DISCUSSION}

In the present article, we were able to identify aberrant expression of genes in the brain of female obese, insulin-resistant, non-ovulating mice. Indeed, after analyzing 84 genes involved in modulating biological processes such as neurotransmitter biosynthesis, uptake, transport, and signaling we identified, after a triplicate real-time PCR confirmation, a total of 34 genes whose expression were found altered in the brain from anovulatory animals.

Among these genes, the $G A B A-A$ receptors were the most abundant up-regulated category responding for $32.2 \%$ ( 11 of 34 genes) of all differentially expressed genes. The second more abundantly affected category of neurotransmitter receptors, in anovulatory brains, was the Cholinergic Receptors Nicotinic (CHRN) accounting for 20.5\% (7 of 34 genes) of all abnormally expressed genes. The third more commonly misbalanced group of genes was the one involved in coding the Neuropeptide Y Receptors responding for $11.7 \%$ (4 of 34 genes) of all differentially expressed genes. The other 12 misbalanced genes were scattered in other classes displayed in Table 1.

It is well known that the feedback regulation of GnRH neurons by steroid hormones is critical to normal reproductive function and occurs in part through altered GABAergic drive to these cells (Qublan and Malkawi, 2005; Zafar, 2005; Rouzi et al., 2006; Freret et al., 2006; Costello et al., 2007a,b). Altered sensitivity to steroid feedback is associated with forms of hypothalamic infertility such as the common reproductive disorder PCOS, a leading cause of infertility in women.

Indeed, in the present study, we were able to show that in our model of anovulation, obesity and insulin resistance, the lack of leptin was followed by a remarkable up-regulation of $G A B A-A$ mRNA receptors that was completely normalized after only 7 days of leptin introduction.

This finding suggests that the GABAergic system may play a role in forms of hypothalamic infertility; however, there is some controversy on whether the GABAergic activity, a known inhibitory pathway, can inhibit GnRH neurons.

GABA inhibits most mature neurons, but this is controversial for GnRH neurons. In fact, GnRH neurons maintain elevated chloride (Chehab et al., 1996), as do other neurons derived from olfactory placode (Mounzih et al., 1997), and may thus be excited by GABA-A receptor activation. Studies using functional approaches to examine GnRH neurons differ as to whether GABA excites or inhibits these neurons (Chehab et al., 1996; Mounzih et al., 1997; Farooqi et al., 2002; Oral et al., 2002), but direct correlations between reduced fertility and reduced GABAergic drive support the former (Zhang et al., 1994; Schubring et al., 1997). Regardless of the response of GnRH neurons to GABAAR activation, GABAARs clearly play a role in fertility regulation.

The different actions of acetylcholine (ACh) are mediated by activation of nicotinic (ionotropic) and muscarinic (metabotropic) classes of receptors. Nicotinic receptors ( $n A C h R s)$ are ligand-gated receptor channels that are cation-specific but do not distinguish readily among cations (Edman and MacDonald, 1978). Both classes of cholinergic receptors are expressed throughout the brain and are abundant in the hypothalamus, where monoaminergic neurons that terminate on GnRH and other peptidergic neurons are located (Goldzieherand Green, 1962). The GnRH neurons of the hypothalamus are innervated by noradrenergic neurons located in the hindbrain, and catecholamines have been implicated in the regulation of $\mathrm{GnRH}$ release. In contrast, there is less evidence for a role of cholinergic innervation in the control of GnRH secretion.

Genetics and Molecular Research 16 (3): gmr16039622 


\section{REFERENCES}

Blanksby SJ and Mitchell TW (2010). Advances in mass spectrometry for lipidomics. Annu. Rev. Anal. Chem. (Palo Alto, Calif.) 3: 433-465. https://doi.org/10.1146/annurev.anchem.111808.073705

Chehab FF, Lim ME and Lu R (1996). Correction of the sterility defect in homozygous obese female mice by treatment with the human recombinant leptin. Nat. Genet. 12: 318-320. https://doi.org/10.1038/ng0396-318

Costello MF, Shrestha B, Eden J, Johnson NP, et al. (2007a). Metformin versus oral contraceptive pill in polycystic ovary syndrome: a Cochrane review. Hum. Reprod. 22: 1200-1209. https://doi.org/10.1093/humrep/dem005

Costello M, Shrestha B, Eden J, Sjoblom P, et al. (2007b). Insulin-sensitising drugs versus the combined oral contraceptive pill for hirsutism, acne and risk of diabetes, cardiovascular disease, and endometrial cancer in polycystic ovary syndrome. Cochrane Database Syst. Rev. 24: CD005552.

Diamanti-Kandarakis E, Kouli CR, Bergiele AT, Filandra FA, et al. (1999). A survey of the polycystic ovary syndrome in the Greek island of Lesbos: hormonal and metabolic profile. J. Clin. Endocrinol. Metab. 84: 4006-4011. https://doi. org $/ 10.1210 /$ jcem.84.11.6148

Diamanti-Kandarakis E (2008). Polycystic ovarian syndrome: pathophysiology, molecular aspects and clinical implications. Expert Rev. Mol. Med. 10: e3. https://doi.org/10.1017/S1462399408000598

Edman CD and MacDonald PC (1978). Effect of obesity on conversion of plasma androstenedione to estrone in ovulatory and anovulator young women. Am. J. Obstet. Gynecol. 130: 456-461. https://doi.org/10.1016/0002-9378(78)90288-0

Farooqi IS, Matarese G, Lord GM, Keogh JM, et al. (2002). Beneficial effects of leptin on obesity, T cell hyporesponsiveness, and neuroendocrine/metabolic dysfunction of human congenital leptin deficiency. J. Clin. Invest. 110: 1093-1103. https://doi.org/10.1172/JCI0215693

Freret S, Grimard B, Ponter AA, Joly C, et al. (2006). Reduction of body-weight gain enhances in vitro embryo production in overfed superovulated dairy heifers. Reproduction 131: 783-794. https://doi.org/10.1530/rep.1.00689

Gavrilova O, Marcus-Samuels B, Graham D, Kim JK, et al. (2000). Surgical implantation of adipose tissue reverses diabetes in lipoatrophic mice. J. Clin. Invest. 105: 271-278. https://doi.org/10.1172/JCI7901

Goldzieher JW and Green JA (1962). The polycystic ovary. I. Clinical and histologic features. J. Clin. Endocrinol. Metab. 22: 325-338. https://doi.org/10.1210/jcem-22-3-325

Mounzih K, Lu R and Chehab FF (1997). Leptin treatment rescues the sterility of genetically obese ob/ob males. Endocrinology 138: 1190-1193. https://doi.org/10.1210/endo.138.3.5024

Oral EA, Simha V, Ruiz E, Andewelt A, et al. (2002). Leptin-replacement therapy for lipodystrophy. N. Engl. J. Med. 346: 570-578. https://doi.org/10.1056/NEJMoa012437

Qublan HS and Malkawi HY (2005). Metformin in the treatment of clomiphene citrate-resistant women with high BMI and primary infertility: clinical results and reproductive outcome. J. Obstet. Gynaecol. 25: 55-59. https://doi. org/10.1080/01443610400025382

Rouzi AA, Ardawi MSM and Path FRC (2006). A randomized controlled trial of the efficacy of rosiglitazone and clomiphene citrate versus metformin and clomiphene citrate in women with clomiphene citrate-resistant polycystic ovary syndrome. Fertil. Steril. 85: 428-435. https://doi.org/10.1016/j.fertnstert.2005.07.1312

Schubring C, Kiess W, Englaro P, Rascher W, et al. (1997). Levels of leptin in maternal serum, amniotic fluid, and arterial and venous cord blood: relation to neonatal and placental weight. J. Clin. Endocrinol. Metab. 82: 1480-1483. https:// doi.org/10.1210/jcem.82.5.3935

Zafar S (2005). Role of metformin in correcting hyperinsulinemia, menstrual irregularity and anovulation in polycystic ovary syndrome. J. Ayub Med. Coll. Abbottabad 17: 54-56.

Zhang Y, Proenca R, Maffei M, Barone M, et al. (1994). Positional cloning of the mouse obese gene and its human homologue. Nature 372: 425-432. https://doi.org/10.1038/372425a0

Genetics and Molecular Research 16 (3): gmr16039622 